\title{
Production of the Lowest Viscosity Waste Cooking Oil Biodiesel by Using Ethanol and Potassium Hydroxide
}

\author{
Mert Gülüm, Atilla Bilgin, and Abdülvahap Çakmak
}

\begin{abstract}
In this study, optimum reaction parameters were determined to produce the lowest kinematic viscosity waste cooking oil biodiesel by using ethyl alcohol as alcohol and potassium hydroxide as catalyst by means of transesterification reaction. Reaction parameters, which influence the transesterification such as catalyst concentration, reaction temperature, reaction time and ethyl alcohol/oil molar ratio, were varied within the ranges of $0.5-1.75 \%, 60-90{ }^{\circ} \mathrm{C}, 60-150$ minute and 6:1-15:1, respectively, and then the effects of these parametric changes on kinematic viscosities of produced biodiesels were investigated. According to results, reaction parameters giving the lowest kinematic viscosity of $4.380 \mathrm{cSt}$ were determined as $\% 1.00$ catalyst concentration, $70{ }^{\circ} \mathrm{C}$ reaction temperature, 120 minutes reaction time and 12:1 ethyl alcohol/oil molar ratio.
\end{abstract}

Index Terms-Waste cooking oil, biodiesel, transesterification, ethyl alcohol, viscosity.

\section{INTRODUCTION}

Renewable fuels has gained attention during the last few decades because of the decreasing oil supply and increasing environmental consciousness [1]. One of these fuels, biodiesel is an attractive alternative to reduce dependence on fuels derived from petroleum [2]. From a chemical point of view, biodiesel can be defined as a group of mono-alkyl esters of long-chain-fatty acids derived from renewable feedstock (vegetable oils, recycled cooking greases or animal fats) [2], [3]. Biodiesel has been of great interest to researchers. This interest is based on a number of great properties as: (1) It is a sulfur-free, non-toxic and biodegradable fuel and provides engine lubricity to low sulfur diesel fuels [4], [5]. (2) It does not contribute to a net rise in the level of carbon dioxide in the atmosphere and leads to minimize the intensity of greenhouse effect [6]. (3) Biodiesel has higher cetane number than diesel fuel, better ignition quality and contains 10 to $11 \%$ oxygen by weight. These characteristics reduce the emissions of carbon monoxide (CO), hydrocarbon ( $\mathrm{HC})$, and particulate matter (PM) in the exhaust gas compared with diesel fuel [4], [7]-[10]. (4) The flash point of biodiesel is higher than that of diesel fuel, which makes biodiesel safer regarding the storage and transport [7]. While biodiesel have numerous advantages, it has also some drawbacks compared with diesel fuel such as higher viscosity, specific gravity, cloud point and pour point temperatures. These specificities have a significant influence on the fuel spray atomization and evaporation characteristics,

Manuscript received April 6, 2016; revised June 3, 2016.

Mert Gülüm and Atilla Bilgin are with Karadeniz Technical University, turkey (e-mail: mertgulumm@gmail.com, bilgin@ktu.edu.tr).

Abdülvahap Çakmak is with Ondokuz Mayıs University, Turkey (e-mail: abdulvahap.cakmak@omu.edu.tr). resulting in changes in the combustion process [11]. Also, the other main drawback is its higher price, which is mainly due to the cost of virgin vegetable oil [12].

Several methods exist for producing biodiesel. The most significant is the transesterification reaction method. In this reaction, vegetable or used oil is added to a mono-hydroxyl alcohol (methanol, ethanol and butanol) in the presence of a basic homogenous catalyst $(\mathrm{NaOH}$ and $\mathrm{KOH})$ to form alcohol esters (biodiesel) and glycerol [3]. Selection of the alcohol is based on cost and performance consideration. For example, ethanol can be produced from agricultural renewable resources, thereby attaining total independence from petroleum-based alcohols such as methanol [12]. Moreover, ethanol has superior dissolving power in vegetable oils [13], is less toxic [14], and produces biodiesel with improved fuel properties (e.g. higher energy content, larger cetane number and stronger oxidation stability) [15]. There are a lot of studies about biodiesel production by means of transesterification reaction in literature as following. Patil and Deng [6] investigated biodiesel production from different non-edible (jatropha and karanja) and edible (corn and canola) vegetable oils with two-step esterification and single-step transesterification process, respectively. Sulfuric acid, potassium hydroxide and methanol were used in these reactions. The esterification process gives yields of 90-95\% and $80-85 \%$ for jatropha and karanja oil biodiesels, while the transesterification process gives yields of $80-95 \%$ and $85-96 \%$ for canola and corn oil biodiesels, respectively. Meher et al. [16] optimized transesterification reaction parameters for Karanja oil biodiesel. Optimum parameters were obtained as $1 \%$ potassium hydroxide as catalyst, 6:1 methanol to oil molar ratio, $65{ }^{\circ} \mathrm{C}$ reaction temperature, 360 $\mathrm{rpm}$ rate of mixing for a period of $3 \mathrm{~h}$. The fatty acid methyl ester yield of karanja oil biodiesel produced under the optimal condition was obtained as $97-98 \%$. Sinha et al. [17] investigated the transesterification process for production of rice bran oil methyl ester. To produce with a maximum yield, the authors optimized the various process variables like temperature, catalyst concentration, methanol to oil molar ratio and reaction time. According to results, the optimum conditions for the transesterification reaction were obtained as $55{ }^{\circ} \mathrm{C}$ reaction temperature, $1 \mathrm{~h}$ reaction time, 9:1 molar ratio and $075 \%$ sodium hydroxide as catalyst. In the study performed by Encinar and his colleagues [18], production of biodiesel from Cynara cardunculus $\mathrm{L}$ was carried out by using ethanol as alcohol and different catalysts (sodium and potassium hydroxide). The operation variables for reaction temperature, catalyst concentration and ethanol/oil molar ratio were ranged as $25-75^{\circ} \mathrm{C}, 0.25-1.50 \mathrm{wt} \%$ and $3: 1-15: 1$, respectively. The optimum parameters giving maximum 
biodiesel yield were found as ethanol/oil molar ratio 12:1, sodium hydroxide as catalyst $\left(1.00\right.$ wt \%) and $75{ }^{\circ} \mathrm{C}$ temperature.

There are also several other researches like mentioned above about specification of optimization parameters of biodiesel production giving the highest ester content or yield in literature. But, there is a scarcity about detailed parametric investigation on the effects of transesterification reaction parameters on kinematic viscosity and density of produced biodiesel. Therefore the main objective of the present work is to optimize the reaction parameters giving the lowest kinematic viscosity biodiesel produced from waste cooking oil, ethanol and potassium hydroxide. Thus, (1) it was tried to solve the high viscosity problem of biodiesel mentioned above, (2) the raw material cost was reduced with the use of waste cooking oil, instead of virgin oil, and (3) more renewable biodiesel having superior fuel properties was produced with use of ethanol instead of methanol.

\section{MATERIALS AND METHODS}

\section{A. Materials}

To produce biodiesel by basic catalyzed transesterification, waste cooking oil was provided from the university canteen. Ethanol of $99.8 \%$ purity and potassium hydroxide of pure grade were of Merck.

\section{B. Production Parameters and Biodiesel Production}

Physical and chemical properties of produced biodiesel are significantly affected by various reaction parameters. In this study, the effects of the following parameters on the kinematic viscosities of produced waste cooking oil biodiesels were investigated.

- Catalyst concentrations, \% (mass of $\mathrm{KOH} / \mathrm{mass}$ of waste cooking oil): $0.50,0.75,1.00,1.25,1.50,1.75$

- Reaction temperatures, ${ }^{\circ} \mathrm{C}: 60,70,80,90$

- Reaction times, minute: 60, 90, 120, 150

- Ethyl alcohol/oil molar ratios: 6:1, 9:1, 12:1, 15:1

The above parameter values were selected as including the ranges in the literature [5], [19]-[22]. The transesterification reaction was carried out in a $1 \mathrm{~L}$ flat-bottomed flask, equipped with a magnetic stirrer heater, thermometer and spiral reflux condenser. Haake Falling Ball Viscometer, Isolab pycnometer, top loading balance with an accuracy of $\pm 0.01 \mathrm{~g}$, Haake Water Bath and stopwatch with an accuracy of $\pm 0.01 \mathrm{~s}$ were used to measure dynamic viscosity and density. Before starting the reaction, a certain amount of potassium hydroxide $(\mathrm{KOH})$ according to chosen catalyst concentration was dissolved in a certain amount of ethyl alcohol $\left(\mathrm{C}_{2} \mathrm{H}_{5} \mathrm{OH}\right)$ depending on alcohol/oil molar ratio in a narrow-neck flask to make alcoholic solution of catalyst. In the flat bottomed flask, this alcoholic solution was added to the $200 \mathrm{~g}$ waste cooking oil that was formerly warmed to about $80^{\circ} \mathrm{C}$ in a beaker. Until a certain time, these reactants were mixed at a certain reaction temperature with stirring speed of $500 \mathrm{rpm}$ by means of the magnetic stirrer heater. Transesterification reaction was carried out with the spiral reflux condenser for avoiding loss of alcohol. Also, reaction temperature was controlled by using the thermometer to remain at a constant temperature during the reaction. At the end of reaction, the resulting product mixture was transferred to a separating funnel. After a day, two phases occurred in the separating funnel. The upper phase consists of ethyl esters (biodiesel) while the lower one consists of glycerol, excess ethanol and the remaining catalyst together with soap. After separation of the two layers by gravity with gliserol, the upper layer (biodiesel) was washed with warm distilled water. Washed biodiesel was heated up to about $100^{\circ} \mathrm{C}$ to remove ethyl alcohol and water residuals.

\section{Density Measurement}

The density of the produced biodiesel was determined by means of Eq. (1) and measurements in accordance with ISO 4787 standard:

$$
\rho_{\text {biodiesel }}=\frac{m_{\text {total }}-m_{\text {pycnometer }}}{m_{\text {water }}} \rho_{\text {water }}
$$

where $\rho$ and $m$ represent density and mass, respectively. In order to minimize measurement errors, all the measurements were conducted three times for each sample and the results were averaged. Details of the measurements were given in [8].

\section{Dynamic and Kinematic Viscosity Measurement}

The dynamic viscosity at $40^{\circ} \mathrm{C}$ was determined in accordance with DIN 53015 standard by using Eq. (2) and making measurements by means of the Haake Falling Ball Viscometer, Haake Water Bath and stopwatch:

$$
\mu_{\text {biodiesel }}=K_{\text {ball }}\left(p_{\text {ball }}-p_{\text {biodiesel }}\right) t
$$

where $\mu_{\text {biodiesel }}$ is dynamic viscosity of produced biodiesel, $K_{\text {ball }}$ is coefficient of the viscometer ball, and $\mathrm{t}$ is falling time of the ball moving between two horizontal line marked on viscometer tube at limit velocity. $K_{\text {ball }}$ and $\rho_{\text {ball }}$ are 0.057 $\mathrm{mPa} . \mathrm{s} . \mathrm{cm}^{3} / \mathrm{g} / \mathrm{s}$ and $2.2 \mathrm{~g} / \mathrm{cm}^{3}$, respectively. The viscosity measurements were also conducted three times for each sample and the results were averaged.

The kinematic viscosity was determined from Eq. (3) by dividing dynamic viscosity to density at same temperature:

$$
v_{\text {biodiesel }}=\mu_{\text {biodiesel }} / \rho_{\text {biodiesel }}
$$

In Eq. (3), if $\mu_{\text {biodiesel }}$ and $\rho_{\text {biodiesel }}$ are in the unit of (cP) and $(\mathrm{kg} / \mathrm{L})$ respectively, then $v_{\text {biodiesel }}$ is obtained in unit of (cSt).

\section{E. Uncertainty Analysis}

The results obtained from experimental studies are generally calculated from measured physical quantities. These quantities have some uncertainties due to uncertainties of measuring tools and measurement systems. Therefore, uncertainty analysis should be applied for proving reliability of the calculated results. In this study, uncertainties of the measured and calculated physical quantities such as dynamic and kinematic viscosities and densities were determined by the method proposed by [23]. According to this method, if the result $\mathrm{R}$ is a given function of the independent variables $x_{1}, x_{2}$ $x_{3}, \ldots, x_{n}$ and $w_{1}, w_{2}, w_{3}, \ldots, w_{n}$ are the uncertainties of each independent variables, then the uncertainty of the result $w_{R}$ is calculated by using the equation: 


$$
w_{R}=\left[\left(\frac{\partial R}{\partial x_{1}} w_{1}\right)^{2}+\left(\frac{\partial R}{\partial x_{2}} w_{2}\right)^{2}+\ldots+\left(\frac{\partial R}{\partial x_{n}} w_{n}\right)^{2}\right]
$$

By using the method (4), the highest uncertainty was determined as $0.0869 \%$, which show that the results have fairly high reliability.

\section{RESUlTS AND DISCUSSION}

Parametric study was started by varying catalyst concentration. After determination of the optimum catalyst concentration, the effects of reaction temperature, reaction time and ethyl alcohol/oil molar ratio on kinematic viscosities of produced biodiesels were investigated, respectively.

\section{A. Effect of Catalyst Concentration}

In order to analyze the effect of catalyst concentration on kinematic viscosity of biodiesel,

- the alcohol/oil molar ratio: 9:1

- reaction temperature: $70{ }^{\circ} \mathrm{C}$

- reaction time: 90 minutes

were kept constant throughout this set of the experiments and catalyst concentration was changed as $0.50,0.75,1.00,1.25$, 1.50 and $1.75 \%$. The influence of catalyst concentration on kinematic viscosity is shown in Fig. 1. It was observed that the kinematic viscosity of produced biodiesel decreases until $1.00 \%$ catalyst concentration, and at this point, it takes a minimum value of $4.472 \mathrm{cSt}$. Then, kinematic viscosity gradually increases with increasing catalyst concentration. According to [24], [25], the viscosity of the produced biodiesel decreases with increasing reaction yield. The inadequate amount of catalyst in reaction medium for low catalyst concentrations (e.g., $0.50 \%$ of potassium hydroxide) reduces yield of the transesterification reaction, and increases kinematic viscosity of produced biodiesel. Moreover, the use of higher catalyst concentration develops yield of the transesterification reaction, and thus the viscosity of the produced biodiesel decreases. On the other hand, if excess catalyst concentration is used, the yield of the transesterification reaction decreases and the viscosity of the produced biodiesel increases because of formation of fatty acid salts (soap), decrease in activity of catalyst and difficulty in separation of glycerol [26], [27].

In the next stage of the study, catalyst concentration of $1.00 \%$ giving the lowest viscosity was kept constant and the other parameters were changed.

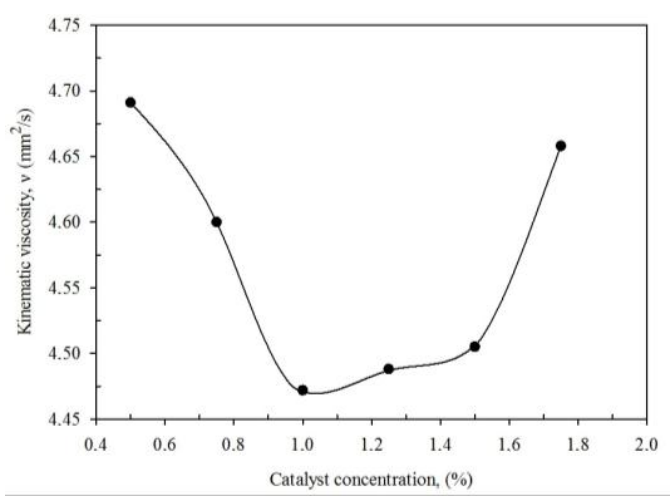

Fig. 1. Variation of kinematic viscosity with respect to catalyst concentration.

\section{B. Effect of Reaction Temperature}

To investigate the effect of reaction temperature on kinematic viscosity of produced biodiesel,

- catalyst concentration: $1.00 \%$

- the alcohol/oil molar ratio: 9:1

- reaction time: 90 minutes

were kept constant throughout this set of the experiments and reaction temperature was changed as $60,70,80$ and $90^{\circ} \mathrm{C}$. The variation of kinematic viscosity with reaction temperature is shown in Fig. 2. According to this figure, as reaction temperature is increased, firstly kinematic viscosity decreases until the reaction temperature of $70^{\circ} \mathrm{C}$, at this point it takes a minimum value of $4.472 \mathrm{cSt}$, and then it gradually increases. A decrease in the yield and thus an increase in the viscosity were observed at low reaction temperatures (e.g., $60^{\circ} \mathrm{C}$ ) since transesterification reaction cannot be effectively completed. With increasing reaction temperature, the yield of the transesterification reaction improves due to higher energy input [26], and thus the viscosity of produced biodiesel decreases. But, at the reaction temperatures beyond boiling point of ethyl alcohol $\left(78.4^{\circ} \mathrm{C}\right)$, kinematic viscosity of produced biodiesel increases due to diminishing of alcohol concentration by evaporating from reaction medium, and saponification and decomposition of esters in biodiesel.

According to results, reaction temperature of $70^{\circ} \mathrm{C}$ giving the lowest viscosity was regarded to be optimal value.

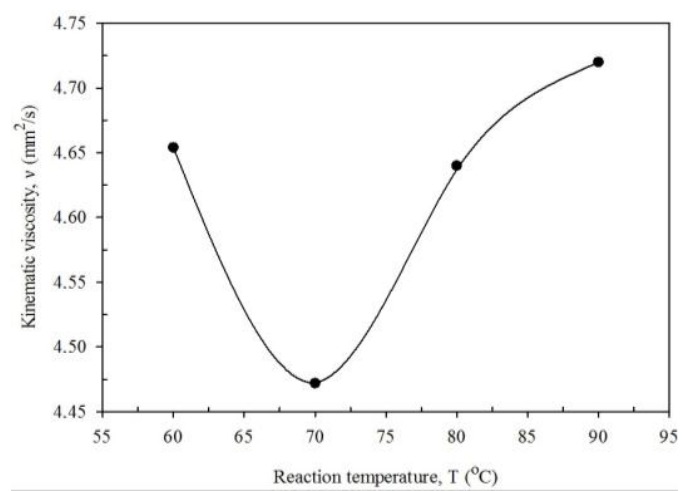

Fig. 2. Variation of kinematic viscosity with respect to reaction temperature.

\section{Effect of Reaction Time}

In order to research the effect of reaction time on kinematic viscosity of biodiesel,

- catalyst concentration: $1.00 \%$

- reaction temperature: $70{ }^{\circ} \mathrm{C}$

- alcohol/oil molar ratio: 9:1

were kept constant throughout this set of the experiments and reaction time was changed as 60, 90, 120 and 150 minutes. Fig. 3 shows the effect of reaction time on kinematic viscosity of produced biodiesel. As seen in this figure, as reaction time is increased, kinematic viscosity of produced biodiesel decreases until the reaction time of 120 minutes, at this time, it takes a minimum value of $4.472 \mathrm{cSt}$, and then it gradually increases. This behavior can be explained by the change of transesterification reaction yield. In short reaction periods, kinematic viscosity of biodiesel is higher because of decreasing the yield of transesterification reaction. When reaction time is increased, kinematic viscosity of biodiesel decreases and makes a minimum value at about 120 minutes 
because of improving reaction yield [27]. However, if reaction time is continued to increase, the transesterification reaction may shift towards reactants and thus viscosity of biodiesel increases.

In the next stage of the study, based on these results, reaction time of 120 minutes giving the lowest viscosity was considered to be an optimum condition.

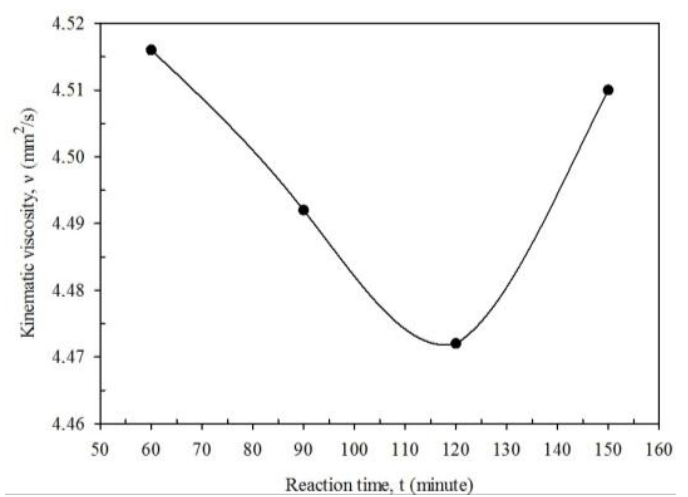

Fig. 3. Variation of kinematic viscosity with respect to reaction time.

\section{Effect of Alcohol/Oil Molar Ratio}

To research the effect of ethyl alcohol/oil molar ratio on kinematic viscosity of biodiesel,

- catalyst concentration: $1.25 \%$

- reaction temperature: $70{ }^{\circ} \mathrm{C}$

- reaction time: 120 minutes

were kept constant throughout this set of the experiments and molar ratio was changed as $6: 1,9: 1,12: 1$ and 15:1. The change of kinematic viscosity with ethyl alcohol/oil molar ratio is shown in Fig. 4. The molar ratio of alcohol to oil is one of the important factors that affect the conversion efficiency as well as production cost of biodiesel. Theoretically, transesterification reaction requires three moles of alcohol for each mole of oil. However, in practice, the molar ratio should be higher than that of stoichiometric ratio in order to drive the reaction towards completion [28]. The minimum kinematic viscosity was obtained as $4.380 \mathrm{cSt}$ at $12: 1$ molar ratio. With further increase in molar ratio (e.g. 15:1), the viscosity tends gradually to increase because use of excess alcohol could be attributed to deactivation of the catalyst and increases in the solubility of the glycerol in the ethyl ester phase. Alcohol/oil molar ratio of 12:1 giving the lowest viscosity was taken to be optimal value.

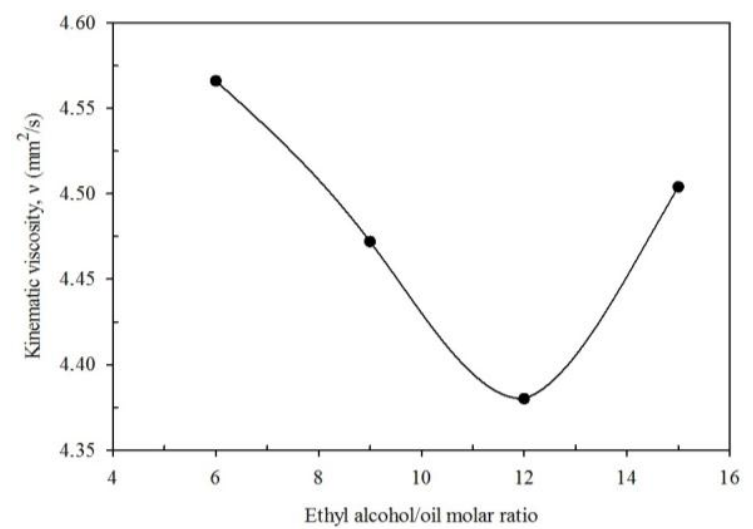

Fig. 4. Variation of kinematic viscosity with respect to alcohol/oil molar ratio.

\section{CONCLUSION}

In this study, the production of the lowest kinematic viscosity waste cooking oil biodiesel were investigated by researching the individual effects of catalyst concentration, reaction temperature, reaction time and ethyl alcohol/oil molar ratio on kinematic viscosity of produced biodiesel. The optimum parameters giving the lowest viscosity of $4.380 \mathrm{cSt}$ were determined that:

- $1.00 \%$ catalyst concentration

- $70^{\circ} \mathrm{C}$ reaction temperature

- 120 minutes reaction time

- 12:1 ethyl alcohol/oil molar ratio.

In the light of this work, for future studies, researchers can be investigated about produced of biodiesels by using different alcohols, oils and catalysts with considering the highest ester yield or the lowest viscosity.

\section{ACKNOWLEDGMENT}

The authors express their gratitude to Karadeniz Technical University Scientific Research Projects Fund for financial support received (Project No: 9745).

\section{REFERENCES}

[1] F. X. Feitosa, M. D. L. Rodrigues, C. B. Veloso, C. L. Cavalcante, J. M. C. G. Albuquerque, and H. B. D. S. Ana, "Viscosities and densities of binary mixtures of coconut+colza and coconut+soybean biodiesel at various temperatures," J. Chem. Eng. Data, vol. 55, pp. 3909-3914, 2010.

[2] L. F. R. Verduzco, B. E. G. Flores, J. E. R. Rodriguez, and A. D. R. J Jacob, "Prediction of the density and viscosity in biodiesel blends at various temperatures," Fuel, vol. 90, pp. 1751-1761, 2011.

[3] C. A. Nogueira, J. F. X. Feitosa, F. A. N. Fernandes, R. S. Santiago, and H. B. D. S. Ana, "Densities and viscosities of binary mixtures of babassu biodiesel + cotton seed or soybean biodiesel at different temperatures," J. Chem. Eng. Data, vol. 55, issue 11, pp. 5305-5310, 2010.

[4] M. Canakci, "Combustion characteristics of a turbocharged DI compression ignition engine fueled with petroleum diesel fuels and biodiesel," Bioresource Technology, vol. 98, pp. 1167-1175, 2007.

[5] D. Karonis, G. Anastopoulos, F. Zannikos, S. Stournas, and E. Lois "Determination of physicochemical properties of fatty acid ethyl esters (FAEE) - diesel fuel blends," SAE Technical Paper, 2009-01-1788.

[6] P. D. Patil and S. Deng, "Optimization of biodiesel production from edible and non-edible vegetable oils," Fuel, vol. 88, pp. 1302-1306, July 2009.

[7] E. Alptekin and M. Canakci, "Determination of the density and the viscosities of biodiesel-diesel fuel blends," Renewable Energy, vol. 33 , pp. 2623-2630, 2008.

[8] M. Gülüm and A. Bilgin, "Density, flash point and heating value variations of corn oil biodiesel-diesel fuel blends," Fuel Processing Technology, vol. 134, pp. 456-464, 2015.

[9] Z. Al-Hamamre and A. Al-Salaymeh, "Physical properties of (jojoba oil+biodiesel), (jojoba oil+diesel) and (biodiesel+diesel) blends," Fuel, vol. 123, pp. 175-188, 2014.

[10] R. A. Candeia, M. C. D. Silva, J. R. C. Filho, M. G. A. Brasilino, T. C. Bicudo, I. M. G. Santos, and A. G. Souza, "Influence of soybean biodiesel content on basic properties of biodiesel-diesel blends," Fuel, vol. 88, pp. 738-743, 2009.

[11] S. H. Yoon, S. H. Park, and C. S. Lee, "Experimental investigation on the fuel properties of biodiesel and its blends at various temperatures," Energy \& Fuels, vol. 22, pp. 652-656, 2008.

[12] J. M. Encinar, J. F. Gonzalez, and A. R. Reinares, "Ethanolysis of used frying oil. Biodiesel preparation and characterization," Fuel Processing Technology, vol. 88, pp. 513-522, 2007.

[13] O. S. Stamenkovic, A. V. Velickovic, and V. B. Veljkovic, "The production of biodiesel from vegetable oils by ethanolysis: Current state and perspectives," Fuel, vol. 90, pp. 3141-3155, 2011.

[14] R. B. Levine, A. Bollas, and P. E. Savage, "Process improvements for the supercritical in situ transesterification of carbonized algal biomass," Bioresource Technology, vol. 136, pp. 556-564, May 2013. 
[15] B. Jin, P. Duan, Y. Xu, B. Wang, F. Wang, and L. Zhang, "Lewis acid-catalyzed in situ transesterification/esterification of microalgae in supercritical ethanol," Bioresource Technology, vol. 162, pp. 341-349, June 2014.

[16] L. C. Meher, V. S. S. Dharmagadda, and S. N. Naik, "Optimization of alkali-catalyzed transesterification of Pongamia pinnata oil for production of biodiesel," Bioresource Technology, vol. 97, pp. 1392-1397, 2006.

[17] S. Sinha, A. K. Agarwal, and S. Garg, "Biodiesel development from rice bran oil: Transesterification process optimization and fuel characterization," Energy Conversion \& Management, vol. 49, pp. 1248-1257, 2008.

[18] J. M. Encinar, J. F. Gonzalez, J. J. Rodriguez, and A. Tejedor, "Biodiesel fuels from vegetable oils: Transesterification of Cynara cardunculos L. oils with ethanol," Energy \& Fuels, vol. 16, pp. 443-450, 2002.

[19] M. S. A. Ginting, M. T. Azizan, and S. Yusup, "Alkaline in situ ethanolysis of Jatropha curcas," Fuel, vol. 93, pp. 82-85, March 2012.

[20] D. D. C. Barbosa, T. M. Serra, S. M. P. Meneghetti, and M. R. Meneghetti, "Biodiesel production by ethanolysis of mixed castor and soybean oils," Fuel, vol. 89, pp. 3791-3794, December 2010.

[21] T. Issariyakul, M. G. Kulkarni, L.C. Meher, A. K. Dalai, and N. N. Bakhshi, "Biodiesel production from mixtures of canola oil and used cooking oil," Chemical Engineering Journal, vol. 140, pp. 77-85, July 2008.

[22] S. M. P. Meneghetti, M. R. Meneghetti, C. R. Wolf, E. C. Silva, G. E. S Lima, L. D. L. Silva, T. M. Serra, F. Cauduro, and L. G. D. Oliveira, "Biodiesel from Castor oil: A comparison of ethanolysis versus methanolysis," Energy \& Fuels, vol. 20, pp. 2262-2265, 2006.

[23] J. P. Holman, Experimental Methods for Engineers, 8th ed. New York, USA: McGraw-Hill, 2012, ch. 3, p. 52.

[24] R. Ghanei, G. R. Moradi, R. TaherpourKalantari, and E. Arjmandzadeh, "Variation of physical properties during transesterification of sunflower oil to biodiesel as an approach to predict reaction progess," Fuel Processing Technology, vol. 92, pp. 1593-1598, August 2011.

[25] G. R. Moradi, S. Dehghani, and R. Ghanei, "Measurements of physical properties during transesterification of soybean oil to biodiesel for prediction of reaction progress," Energy Conversion and Management, vol. 61, pp. 67-70, September 2012.

[26] B. B. Uzun, M. Kilic, N. Ozbay, A. E. Putun, and E. Putun, "Biodiesel production from waste frying oils: Optimization of reaction parameters and determination of fuel properties," Energy, vol. 44, pp. 347-351, August 2012.

[27] J. M. Encinar, J. F. Gonzalez, and R. A. Rodriguez, "Biodiesel from used frying oil, variables affecting the yields and characteristics of the biodiesel," Ind. Eng. Chem. Res., vol. 44, pp. 5491-5499, 2005.

[28] A. S. Ramadhas, S. Jayaraj, and C. Muraleedharan, "Biodiesel production from high FFA rubber seed oil," Fuel, vol. 84, pp. 335-340, 2005.

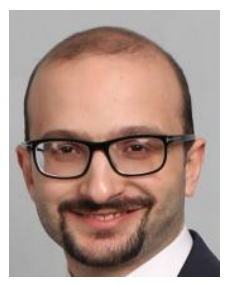

Mert Gülüm received his master's degree from Karadeniz Technical University, Turkey in 2014. He is working at Karadeniz Technical University as a PhD candidate research assistant. His areas of interest are biodiesel production, combustion, fuels, diesel engines.

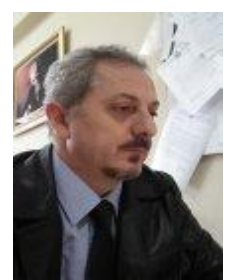

Atilla Bilgin received his master's degree in 1988, and $\mathrm{PhD}$ degree in 1994 from Karadeniz Technical University in Turkey. He is working at Karadeniz Technical University as a professor doctor. His areas of interest are combustion, fuels, engines, computational fluid dynamic, exergy analysis, thermodynamic analysis.

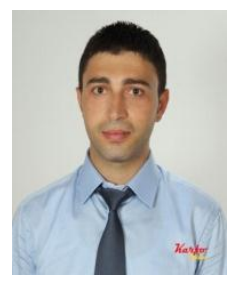

Abdülvahap Çakmak received his MSc degree in mechanical engineering from Karadeniz Technical University, Trabzon, Turkey in 2014. He is currently a $\mathrm{PhD}$ student at the same university and also he is working as a lecturer at Ondokuz Mayis University, Samsun, Turkey. His research topics are internal combustion engine, energy and exergy analysis and biodiesel. 
Solar and Wind Energy 
